\title{
Sustainability of transport biofuels from a legal perspective
}

\author{
Evgenia Pavlovskaia \\ Law Faculty, Lund University, Sweden
}

\section{Email address:}

evgenia.pavlovskaia@jur.lu.se

\section{To cite this article:}

Evgenia Pavlovskaia. Sustainability of Transport Biofuels from a Legal Perspective. International Journal of Environmental Protection and Policy. Vol. 1, No. 4, 2013, pp. 88-93. doi: 10.11648/j.ijepp.20130104.17

\begin{abstract}
The article investigates the notion of transport biofuels, their possible advantages and disadvantages in comparison to traditional fossil fuels, and sustainability requirements that need be stated to their quality and production methods from a legal perspective. The research results indicate that the understanding of what makes the quality and production of transport biofuels sustainable is still unclear. Sustainability parameters for biofuels will differ depending on the types and purposes of biofuel production. There is no clearly agreed definition on what biofuels, and particularly sustainable biofuels are. The task of law in this situation can be to contribute to the sustainable production of biofuels through the use of the traditional and newly emerging legal approaches and instruments, such as e.g. sustainability criteria for biofuels in Directive 2009/28/EC.
\end{abstract}

Keywords: Transport Biofuels, Sustainable Biofuels, Use of Genetically Modified Organisms, EU Biofuel Policy

\section{Introduction}

In 2009, two EU Directives 2009/28/EC [1] and 2009/30/EC [2] came into force [3]. They constituted a legal framework for the production and use of sustainable biofuels in EU, particularly in the transport sector. The EU Directives contains sustainability requirements to biofuels in the form of binding sustainability criteria. The fulfillment of these criteria is a necessary requirement for biofuels to count towards the EU mandatory 2020 renewable energy targets and to get governmental subsidies [4].

To enforce and implement the EU Directives 2009/28/EC and 2009/30/EC in an efficient way, it has become important and urgent to get a clearer picture of what transport biofuels as a product are and what makes their production sustainable. The objective of this article is, thus, to research and generate a deeper understanding about (a) the notion of transport biofuels; (b) their possible advantages and disadvantages in comparison to traditional fossil fuels; and (c) requirements that need be stated to the quality of biofuels and their production, in order to promote and safeguard their sustainability. The research is done from the perspective of the current EU legislation on sustainable transport biofuels. The rapid development of technology, policies and law in this area, which causes changing preconditions and circumstances, is taken into account.

\section{What are Transport Biofuels}

The market of biofuels is a relatively new market that is characterized by speedy development and use of new technologies, which in many cases have governmental support, for example in the form of subsidies and favorable taxation. The increase in the biofuel production and use is observed in a lot of countries in different parts of the world, such as in US, Canada, Brazil, EU, China, Japan, Ukraine, Indonesia, etc.

Biofuels are a source of renewable energy. There are some differences in the way this concept is defined by scientists, and there is no internationally agreed definition. [5] In a simple way, biofuels can be defined as solid, liquid or gaseous fuels derived from organic or recently dead material (not more than 20 - 30 years old), such as plants, animals or their by-products. Examples of liquid biofuels are bioethanol, biodiesel, biobutanol and biomethanol. Examples of gaseous biofuels are biogas and biohydrogen. Liquid biofuels can be used either purely, for example $100 \%$ bioethanol and $100 \%$ biodiesel, or in various mixtures, such as $10 \%$ bioethanol and $90 \%$ the traditional gasoline; or $2 \%$ biodiesel and $98 \%$ the traditional diesel.

Biofuels are distinguished from traditional fossil fuels, which are produced from long dead biological material. Theoretically, biofuels can be produced from any biological 
carbon source, including manufactural or municipal waste and residues of biological origin from agriculture, forest and related industries. Most commonly, biofuels are made by extracting oil from oleaginous plants, for example sunflowers, or by fermentation of the sugars in cereals such as wheat and maize. Wood and its by-products can also be converted into biofuels. At present, biofuels in the transport sector are mainly used as fuels for road motor vehicles.

There are two well-established strategies of producing liquid biofuels, which are particularly interesting for the transport sector. One is to grow crops high in sugar, such as sugar cane, sugar beet and sweet sorghum, or in starch, such as corn and maize, and then use yeast fermentation to produce ethanol. The second strategy is to grow plants that contain high amounts of vegetable oil, such as oil palm, soybean, algae, jatropha or pongamia pinnata. When these oils are heated, their viscosity is reduced, and they can be burned directly in a diesel engine, or they can be chemically processed to produce fuels such as biodiesel. Wood and its by-products can be converted into biofuels such as woodgas, methanol or ethanol fuel. It is also possible to make cellulosic ethanol from non-edible plant parts, but this can be difficult to accomplish economically.

Most often used forms of biofuels are bioethanol, biodiesel and biogas. Bioethanol is a biofuel substitute for petrol. [6] It is manufactured from cereal based crops, mainly wheat in the UK; sugar beet and maize, soyabeans and sugarcane in US and the South America. Biodiesel is a biofuel substitute for diesel. It is produced from oilseed based crops - mainly oilseed rape in the UK, and palmoil in the South East Asia. [7] Bioethanol and biodiesel are classified as the first generation biofuels, or biofuels of an agricultural origin. They are derived from raw materials that can be used in food production.

Biogas is a biofuel substitute for natural gas. [8] It can be produced from organic waste materials including animal waste and waste generated from municipal, commercial and industrial sources through the process of anaerobic digestion. Biogas manufactured from waste belongs to the second generation biofuels. This generation consists of biofuels from non-food crops including cellulosic biofuels, and special-energy-or-biomass crops as for example Miscanthus.

Many types of biofuels are under development, such as biohydrogen, biomethanol, DMF, Bio-DME, and Fischer-Tropsch diesel. Genetically modified organisms (GMOs) as substance for biofuel production is another emerging field, which effects on environment should be researched.

Production of transport biofuels can be divided in two main stages: (a) farming of crops for biofuels of an agricultural origin, or using other materials and technologies to prepare the substance for manufacturing of biofuels; and (b) manufacturing of transport biofuels from the prepared substance. Both these stages should be sustainable, [9] though they require different approaches and criteria of sustainability. For the first stage, it is more practical to apply approaches that are typical for sustainable agriculture. For the second stage, strategies used for similar production processes should be considered.

Regarding the first stage, studies have shown that crops for biofuels of an agricultural origin, if properly placed in the landscape, have potential to increase productivity of land types, provide diversity of markets for farmers, who produce food crops and animals, and could contribute to ecosystem services. They could serve as riparian buffers, filter strips and nutrient traps and could stabilize fragile land on a gentle slope. They could replace at least some of the non-commercial crops. [10] Further investigations have shown that if certain non-eatable plants for biofuel production are grown in an appropriate landscape, they can provide biofuel substance and enhance environmental quality and the quality of the resource base. [11]

Use of genetically modified organisms for the cultivation of energy crops has the potential to result in yield increase and less need for pesticides. This may accelerate the spreading of genetic engineering for agriculture, despite the reluctance of many involved actors. There is an opinion that co-existence of genetically engineered and conventional agriculture will not last long: it will only be a matter of time until a less hazardous form of genetic engineering spreads out, and even food crops become affected. [12] Possibly, genetically modified organisms should be discussed and regulated as a separate area, not restrictively in connection to biofuel production.

Considering the second stage of biofuel production, warnings have been made that water use for converting the prepared biofuel substance to the final product can create competition for water. [13] As an example, the amount of water required for processing biofuel substance into ethanol is estimated to be 2-6 gallons per gallon of ethanol produced. It can be recommended that biofuel refineries are located close to where the biofuel substance is produced. [14]

Biofuels sustainability has environmental, economic and social impacts that all interconnect. Tradeoffs among biofuels can vary widely. They depend on the type of the used biofuels and where crops for them are grown. [15] There is a need to consider, evaluate and explicitly compare implementation results for biofuel sustainability criteria in various frameworks and standards. Biofuel industry can suffer from referring to many sustainability issues, if not implemented in the right way. [16] The precautionary principle, which is an established practice in environmental law, suggests a careful approach to biofuel production, until a clearer understanding of their environmental impacts, based on scientific knowledge, emerges. [17] The precautionary principle also calls for caution against relying much on a single type of fuels in the transport sector, when there are alternative solutions and technologies that can be possibilities for the future. [18] 


\section{Advantages and Disadvantages of Transport Biofuels in Comparison to Traditional Fossil Fuels}

Transport biofuels have a range of advantages in comparison to the traditional fossil fuels. Bearing in mind that resources of oil and natural gas are limited, [19] and that it is necessary to find alternative sources of energy instead of them, biofuels can be seen as one of very promising future possibilities. [20] Another aspect is that mixtures with low percentage of biofuels do not demand any technical changes in a car engine, which is convenient practically.

Partial use of biofuels instead of the traditional fossil fuels decreases the dependence of countries on oil producing nations and oil crises. Biofuels have the potential to reduce greenhouse gas (GHG) emissions, [21] when compared to the conventional transport fuels [22]. Biofuels are biodegradable and less toxic than fossil fuels. [23] They can, therefore, improve air quality. Biofuels have a potential to be cheaper than fossil fuels, if biofuel technologies become more effective economically. [24] In general, biofuels can have a positive effect on energy prices. Production of biofuels can lead to a wider economic growth and increased employment opportunities. It can promote rural development and access to energy in poorer countries. [25]

Together with the improvement of technological possibilities, the development of legal frameworks that support biofuels is taking place, both at national and international levels. This creates a reliable basis for investments and further improvement of biofuel production processes. Under these conditions it is especially important to safeguard that the quality of biofuels is sustainable. Elaboration of sustainability criteria for biofuels and their use in legal frameworks becomes a significant tool in promoting and protecting sustainability.

As far as disadvantages of biofuels are concerned, the production of biofuels involves large amounts of additional land use, which can damage the existing eco-systems. Biofuels become a profitable opportunity for farmers, who may grow crops for biofuel production instead of food production. This can increase food prices [26] and cause a rise in inflation. Biofuels' consumption in a motor vehicle engine is higher than that of petrol. The total amount of energy input into the production of biofuels remains high and unfavorable. It is uncertain to what extent burning of biofuels reduces GHG emissions, when compared to the traditional fossil fuels.

Current costs of biofuels are much higher than costs of petrol and diesel. Subsidies are needed to make biofuels competitive. [27] Biofuels, for example bioethanol, are less suitable for use in low temperatures than the conventional fuels for transport.

\section{Sustainability Requirements for Transport Biofuels}

Environment reacts according to natural laws, not according to legal documents we create. Laws of nature cannot be neglected. The world economy and production must therefore be limited to the carrying capacity of the Earth's biosphere and ecosystems. [28] Our social and economic development and supporting legislation should be adopted to environmental laws, so that the progress of our society does not result in an environmental collapse. [29] At the same time it is difficult not to agree that legal rules can influence the environment negatively.

Regarding biofuels that are an emerging field for national and international laws, the task of legislation can be to create well-functioning legal frameworks that will preserve the environment and facilitate economic and social growth. It can be discussed whether the goal of the biofuel legislation should be formulated as sustainable development and sustainability of the biofuel industry, which includes sustainable production, trade and use of biofuels. Preservation and improving of different ecological qualities like air, soil and water can under such conditions be natural environmental sub-goals.

It can be suggested that the production of biofuels should include minimum levels of GHG performance, criteria on biodiversity and rewards for the use of feedstock diversifying the raw material for biofuels, such as lignocellulosic material for the production of the second generation biofuels. A transfer of clean technologies to developing countries should be encouraged. Transportation and storage of biofuels need be a subject of special analysis as these factors are important in the biofuel supply chain. According to the data from 2003, transportation accounted for almost $40 \%$ of the total costs for biofuels.

Different types of biofuels are in demand of different criteria for sustainable production. There is a set of general aspects suggested by Börjesson, which can be used to evaluate the environmental impact of biofuels. They are:

- consumption of fuels in a motor vehicle engine;

- the amount of agricultural land needed for production;

- utilization of by- and resting products; and

- $\quad$ emissions of methane during the growth of crops. [30]

An interesting question is what type of a producer is able to manufacture environmentally sustainable biofuels. Large companies can have better financial, technical and scientific possibilities to assess relevant sustainability factors and to operate according to the assessment. Large companies can have more opportunities to use the best available technologies. Their access to knowledge and to the latest scientific news in their production sphere is better. It is easier for them to organize and pay for the process of certification. There will be an environmental winning, if large companies, and not small-scale individual producers, organize the production of transport biofuels and raw materials for them. 
From other points of view, first of all social, a shift of landownership to big farms that are owned by foreign investors is not good for local communities. Small scale production of agricultural products can have environmental advantages, for example in the form of less pressure on biodiversity.

Large scale environmental issues, like additional pressure on pristine land, cannot be assessed on a company or farm basis. A way out may be to assign certain conversion values to different states. [31]

Obviously, sustainability requirements for biofuels would differ for different types of biofuel production. Where biofuels are aimed at providing local fuel security and rural development, sustainability issues will be different from where biofuels are being produced for export as a global replacement to the traditional fossil fuels. [32]

\section{Reflections and Conclusions}

Biofuels can be seen as one of very promising future solutions in the transport sector as a substitute or rather a complement to the traditional fossil fuels and other technological innovations. However, the production, transportation and use of biofuels require more research, assessment of the achieved results and possibly binding legal regulations. The problem rooted here is that biofuels and the whole production branch need be sustainable.

Transport biofuels have a variety of advantages in comparison to the traditional fossil fuels. Thus, they help to avoid dependence on oil and natural gas and their imports. They have the potential to reduce GHG emissions, to promote a wider economic growth, especially in developing countries, and to increase employment opportunities. Nevertheless, there is still much uncertainty in the way sustainability of biofuels and their production methods is defined and understood. There seems to be a consensus that biofuel sustainability has environmental, economic and social impacts that all interconnect, which is in line with the frequently referred to definitions of sustainable development and sustainability.

The central issues of environmental sustainability for biofuels and their production methods, which have been highlighted and discussed in the latest investigations, are cautious and efficient use of land and water resources, preservation of biodiversity and existing eco-systems, reduction of GHG emissions through the whole production chain and avoiding competition with the market of food supply. The issue of genetically modified organisms cultivated for biofuel production should possibly be addressed as a separate and very serious issue. The use of genetically modified organisms can cause irreversible environmental damage. Therefore, additional cautions should be taken here. The precautionary principle established in environmental law suggests that this production area should be thoroughly researched first, until a clearer evidence-based understanding of genetically modified organisms and their consequences for the environment is gained. This production area should probably be regulated through the means of law, in order to avoid unnecessary risks.

Among the weak sides of the today's development in the sphere of biofuels, it can be named that there is no internationally agreed definition on what biofuels, and particularly transport biofuels are. [33] A large variety of biofuel types used for different purposes, including electricity and heating and cooling can be distinguished. Many types of biofuels are still under development or in a testing stage. From a legal perspective, a harmonized, widely-accepted definition of biofuels and their most commonly used types can be recommended. This would create more order and make the use of the concepts easier.

Sustainability requirements for biofuels will differ depending on the types and purposes of biofuel production. Sustainability issues for small-scale biofuel production for local purposes will be different from sustainability issues for biofuels that are produced as a global replacement to the traditional fossil fuels. Large-scale production of biofuels should be carefully planned. The task of law in this case may be to contribute to the sustainable production of biofuels through the use of the traditional and newly emerging legal approaches and instruments. Clearly defined sustainability criteria for a product or a production branch incorporated in a legal framework, as it has been done in Directive 2009/28/EC, can be an illustrative example.

There is a need to analyze, evaluate and explicitly compare implementation results for sustainability criteria for biofuels applied in various legal frameworks and voluntary sustainability standards. There is also a need for further extensive research.

\section{Acknowledgements}

I would like to thank the Law Faculty at Lund University, Sweden, and Vilhelm Persson, its Head, for providing extremely convenient research conditions. I would like to express my deep gratitude to Annika Nilsson, Karin Ericsson and Bengt Lundell, my research supervisors, and Carl Dalhammar, my critical opponent, for their guidance and useful commentaries on the present research work. My special thanks are extended to the Johan and Jakob Söderberg Funding in Stockholm for its financial support.

\section{References}

[1] Directive 2009/28/EC on the promotion of the use of energy from renewable sources and amending and subsequently repealing Directives 2001/77/EC and 2003/30/EC.

[2] Directive 2009/30/EC (on the quality of transport fuels) amending Directive 98/70/EC as regards the specification of petrol, diesel and gas-oil and introducing a mechanism to monitor and reduce greenhouse gas emissions and amending Council Directive 1999/32/EC as regards the specification of fuel used by inland waterway vessels and repealing Directive 93/12/EEC 
[3] Haberl, H., Sprinz, D., Bonazountas, M., Cocco, P., Desaubies, Y., Henze, M., ... \& Searchinger, T. (2012). Correcting a fundamental error in greenhouse gas accounting related to bioenergy. Energy policy, 45, 18-23, p. 21.

[4] Article 17.1 in Directive 2009/28/EC.

[5] One of the difficulties is that the term "biofuel" does not refer to a single, fully developed technology or even a single, uniform type of fuel. All biofuels are energy sources derived from biomass; see Jensen, M., \& Andersen, A. H. (2013). Biofuels: a contested response to climate change. Sustainability: Science, Practice, \& Policy, 9(1), 42-56.

[6] Li, Q., Xu, J., Du, W., Li, Y., \& Liu, D. (2013). Ethanol as the acyl acceptor for biodiesel production. Renewable and Sustainable Energy Reviews, 25, 742-748, p. 747.

[7] A possible definition for biodiesel is that it is biofuel made for diesel engines from agricultural co-products and by-products such as vegetable oils and animal fats; see Diaz, M. (2013). BIODIESEL FEEDSTOCK PRE-TREATMENT STATION, p. 7.

[8] Bansal, T., Tripathi, N., \& Chawla, G. (2013). Upgradation of biogas using combined method of alkaline water scrubbing and adsoption through carbon molecular sieve. In Proceedings of the International Conference on Global Scenario in Environment and Energy, Bhopal, Madhya Pradesh, India, 14-16 March 2013. (Vol. 5, No. 2, pp. 886-890). Sphinx Knowledge House, p. 886; Chmielewski, A. G., Urbaniak, A., \& Wawryniuk, K. (2013). Membrane enrichment of biogas from two-stage pilot plant using agricultural waste as a substrate. Biomass and Bioenergy, $\mathrm{p}$. 1.

[9] There is a wide-spread recognition that to be adopted successfully the production of biofuels should be sustainable; see e.g. Borowitzka, M. A., \& Moheimani, N. R. (2013). Sustainable biofuels from algae. Mitigation and Adaptation Strategies for Global Change, 18(1), 13-25, p. 13.

[10] National Research Council of the National Academies (2010), Toward Sustainable Agricultural Systems in the 21st Century, p. 252.

[11] National Research Council of the National Academies (2010), Toward Sustainable Agricultural Systems in the 21st Century, p. 252; other positive impacts can be to help farmers maintain their profitability and prevent negative effects of land abandonment on biodiversity; see Harvolk, S., Kornatz, P., Otte, A., \& Simmering, D. (2013). Using existing landscape data to assess the ecological potential of Miscanthus cultivation in a marginal landscape. GCB Bioenergy, p. 1.

[12] Ekardt, F., von Bredow, H. (2011), Managing the Ecological and Social Ambivalences of Bioenergy: Sustainability Criteria Versus Extended Carbon Markets, p. 459.

[13] Recent research indicates that demands on water supply are increasing due to growing population, more use per capita, migration of people, economic activity, and the impacts of climate change. Many regions of the world are experiencing increasing water scarcity. Water use requirements for crops for biofuels of an agricultural origin depend on the type of crops, the location where they are grown and how they are managed; see Gopalakrishnan, G., Negri, M. C., Wang, M., Wu, M., Snyder, S. W., \& Lafreniere, L. (2009). Biofuels, land, and water: a systems approach to sustainability. Environmental science \& technology, 43(15), 6094-6100, p. 6094.
[14] National Research Council of the National Academies (2010), Toward Sustainable Agricultural Systems in the 21st Century, p. 252.

[15] Robertson, G. P., Dale, V. H., Doering, O. C., Hamburg, S. P., Melillo, J. M., Wander, M. M., \& Parton, W. (2008). Agriculture-sustainable biofuels redux. Science, 322(5898), p. 49.

[16] National Research Council of the National Academies (2010), Toward Sustainable Agricultural Systems in the 21st Century, p. 252.

[17] The present knowledge about sustainability of biofuels and their production methods is still in question. Many research studies in this field are inconsistent; see Ziolkowska, J. R. (2013). Evaluating sustainability of biofuels feedstocks: A multi-objective framework for supporting decision making. Biomass and Bioenergy, p. 2.

[18] Lin, J. (2010), The Sustainability of Biofuels: Limits of the Meta-Standard Approach, in the Governance of Clean Development, Working Paper 011, December 2010, p. 11.

[19] Mandolesi de Araújo, C. D., de Andrade, C. C., de Souza e Silva, E., \& Dupas, F. A. (2013). Biodiesel production from used cooking oil: A review. Renewable and Sustainable Energy Reviews, 27, 445-452, p. 445.

[20] Biofuels have the potential to replace or reduce the dependence on the traditional fossil fuels; for further information see Brown, R. J., Keates, A. C., \& Brewer, P. J. (2010). Sensitivities of a Standard Test Method for the Determination of the $\mathrm{pHe}$ of Bioethanol and Suggestions for Improvement. Sensors, 10(11), 9982-9993, p. 9983.

[21] The transport sector is estimated today to be one of the largest contributors to GHG emissions. It is also the sector with the highest growth rate of GHG emissions; see Kohler, J. (2013). 7 Moving away from the motor car. The challenge of transition to low carbon vehicles. Creating a Sustainable Economy: An Institutional and Evolutionary Approach to Environmental Policy, 21, 135, p. 135.

[22] Latest research based on the life cycle assessment (LCA) of the whole production process has shown that, unlike what has been anticipated, biofuels of an agricultural origin can provide a little to no benefits for GHG emission savings compared to the traditional fossil fuels. The achieved results depend much on the production methods; for further information see Kendall, A., \& Yuan, J. (2013). Comparing life cycle assessments of different biofuel options. Current opinion in chemical biology, p. 1.

[23] Mandolesi de Araújo, C. D., de Andrade, C. C., de Souza e Silva, E., \& Dupas, F. A. (2013). Biodiesel production from used cooking oil: A review. Renewable and Sustainable Energy Reviews, 27, 445-452, p. 445.

[24] A large variety in prices can be observed. As an example, bioethanol produced from sugarcane in Brazil is three or four times cheaper than bioethanol produced from corn in the USA; see Alonso-Pippo, W., Luengo, C. A., Alonsoamador Morales Alberteris, L., García del Pino, G., \& Duvoisin Junior, S. (2013). Practical implementation of liquid biofuels: The transferability of the Brazilian experiences. Energy Policy, p. 71.

[25] Holden, E., \& Gilpin, G. (2013). Biofuels and Sustainable Transport: A Conceptual Discussion. Sustainability, 5(7), 3129-3149, p. 3130. 
[26] Shi, X., Goto, S. (2011), Harmonizing Biodiesel Fuel Standards in East Asia: Current Status, Challenges and Way Forward, p. 22.

[27] Up till now the production of biofuels has to a large extent been supported by national governments; see Holden, E., \& Gilpin, G. (2013). Biofuels and Sustainable Transport: A Conceptual Discussion. Sustainability, 5(7), 3129-3149, p. 3130.

[28] Aras, G., Crowther, D. (2009), Corporate Sustainability Reporting: A Study in Disingenuity?, Journal of Business Ethics 2009, 87, pp. 279-288, Springer 2008, DOI 10.1007/s10551-008-9806-0, p. 280; Spangenberg, J., H. (2013), Pick Simply the Best: Sustainable Development is About Radical Analysis and Selective Synthesis, not About Old Wine in New Bottles, Helmholtz Centre for Environment Research, Halle/Saale, Germany, Sustainable Development Sust. Dev. 21, 101-111 (2013), p. 102.
[29] Westerlund, S. (2003), Miljörättsliga grundfrågor 2.0, Institutet för miljörätt (IMIR), Björklinge, p. 7.

[30] Börjesson, P. (2009), Contribution to the Conference on Climate Adaptation, 25 February 2009, Alnarp, Sweden.

[31] Delzeit, R., Holm-Müller (2009), Steps to discern sustainability criteria for a certification scheme of bioethanol in Brazil: Approach and difficulties, p. 668.

[32] Von Maltitz, G. P., \& Setzkorn, K. A. (2013). A typology of Southern African biofuel feedstock production projects. Biomass and Bioenergy, p. 14.

[33] This is in spite of the fact that Directive 2009/28/EC provides definitions of such concepts as biofuels, biomass, bioliquids; see Article 2 there. 